\title{
Suicidal ideation, anxiety, and depression in patients with multiple sclerosis
}

\author{
Ideação suicida, ansiedade e depressão em pacientes com esclerose múltipla \\ Carlos Bernardo Tauil1,2,5, Talyta Cortez Grippe 1,5, Ronaldo Maciel Dias', Rafael Paternò Castello Dias-Carneiro ${ }^{3}$, \\ Narel Moita Carneiro ${ }^{1}$, Ana Carolina Rodrigues Aguilar ${ }^{1}$, Flávia Martins da Silva', Felipe Bezerra², \\ Leonardo Kenzo de Almeida², Vitoria Lana Massarente ${ }^{3}$, Elaine de Carvalho Giovannelli ${ }^{3}$, Charles Peter Tilbery ${ }^{3}$, \\ Carlos Otávio Brandão ${ }^{4}$, Leonilda Maria B Santos ${ }^{4}$, Leopoldo dos Santos-Neto ${ }^{5}$
}

\begin{abstract}
Psychiatric disorders frequently occur in patients with multiple sclerosis (MS); however, limited reports are available on these comorbidities. We aimed to investigate the relationships among MS, anxiety, depression, and suicidal ideation. Methods: One hundred and thirty two patients with relapsing-remitting MS were evaluated using the Expanded Disability Status Scale, Beck Depression Inventory-II (BDI-II), Beck Scale for Suicide Ideation (BSI), and Hospital Anxiety and Depression Scale. Results: A hierarchical regression analysis was performed to evaluate the variables. The regression equation significantly predicted the BSI score $(R 2=0.306$; adjusted R2 = $0.273 ; F(9$, $125)=9.18 ; p<0.0005)$, and the BDI-II score was the only variable that contributed significantly to this model ( $<<0.0005)$. Conclusions: A high prevalence of depression and anxiety, and a higher rate of suicidal ideation were identified in MS patients compared to the general population. The presence of depressive symptoms appeared to have a direct influence on the risk of suicide.
\end{abstract}

Keywords: multiple sclerosis; suicidal ideation; anxiety; depression; risk factors; signs and symptoms.

RESUMO

Transtornos psiquiátricos frequentemente ocorrem em pacientes com esclerose múltipla (EM). No entanto, os artigos sobre estas comorbidades são limitados. Pretendemos investigar as relações entre EM, ansiedade, depressão e ideação suicida. Métodos: Cento e trinta e dois pacientes com EM remitente-recorrente foram avaliados usando a Escala de Estado de Incapacidade Expandida, Inventário de Depressão de Beck-II (IDB-II), Escala de Beck para Ideação de Suicídio (BSI) e Escala de Ansiedade e Depressão. Resultados: Uma análise de regressão hierárquica foi realizada para avaliar as variáveis. A equação de regressão previu significativamente o escore $B S I(R 2=0,306 ; R 2$ ajustado = 0,273; $F(9,125)$ = 9,18; $p<0,0005)$ e o escore no IDB-II foi a única variável que contribuiu significativamente para este modelo ( $p<0,0005)$. Conclusões: Uma alta prevalência de depressão e ansiedade e uma maior taxa de ideação suicida foram identificadas em pacientes com EM em comparação com a população em geral. A presença de sintomas depressivos pareceu ter uma influência direta no risco de suicídio.

Palavras-chave: esclerose múltipla; ideação suicida; ansiedade; depressão; fatores de risco; sinais e sintomas.

Multiple sclerosis (MS) is a chronic inflammatory and degenerative disease of the central nervous system that predominately affects women (women:men, 3:1) and individuals aged 20 to 40 years $^{1}$. In this disease, autoimmune mechanisms cause an inflammatory cascade that eventually destroys the myelin, oligodendrocytes, and axons. Involvement of the white and gray matter produces clinical signs and symptoms that cause cumulative physical deficits, disability, and cognitive and psychological alterations. The clinical manifestations of MS include fatigue, sensory and motor deficits, sphincter alterations, optic neuritis, diplopia, cerebellar signs, gait changes, spasticity, and cognitive dysfunction ${ }^{1}$. Given the wide range of symptoms and presentations, the patients' quality of life, including their social and professional lives, are greatly affected. Currently, the etiology of MS is unknown, but genetic studies suggest that the disease results from complex interactions between genetic susceptibility and environmental factors ${ }^{1,2,3}$.

\footnotetext{
${ }^{1}$ Hospital de Base de Brasília, Departamento de Neurologia, Brasília DF, Brasil;

Universidade Católica de Brasília, Brasília DF, Brasil;

${ }^{3}$ Santa Casa de São Paulo, Disciplina de Neurologia, Centro de Atendimento e Tratamento da Esclerose Múltipla, São Paulo SP, Brazil;

${ }^{4}$ Universidade de Campinas, Departamento de Neuroimunologia, Campinas SP, Brasil;

5Universidade de Brasília, Departamento de Medicina Interna, Brasília DF, Brasil.

Correspondence: Carlos Tauil; SHIN QL15, cj 7 / casa 14; 71535-275 Brasília DF, Brasil; E-mail: cbtauil@gmail.com

Conflict of interest: There is no conflict of interest to declare.

Received 19 September 2017; Received in final form 15 January 2018; Accepted 03 February 2018.
} 
In addition to interfering with daily activities, the pain symptoms experienced by patients with MS have also been linked to severe depression ${ }^{4}$. Fatigue, another common symptom in patients with MS, may also be related to affective disorders, including depression. Thus, pain, fatigue, and depression may occur in conjunction with MS, and are often referred to as a set of symptoms in these patients ${ }^{1}$.

Psychiatric disorders are frequently present in patients with MS, as higher incidences of mood disorders and anxiety have been found in these patients compared with age-matched healthy individuals ${ }^{4}$. Approximately $25 \%$ of patients with MS suffer from depression, compared with only $5 \%$ of the general population. In addition, depressive symptoms can affect up to $50 \%$ of patients with MS, and depression can occur at any time during the course of the disease ${ }^{3}$. The mood disorders in these patients may be either a direct or indirect result of the medication used to treat MS or the so-called disease-modifying therapies, as adverse psychological effects of various medications have been described ${ }^{2.3}$. Moreover, the mood disorders may be the result of the psychological reactions and distress induced by the diagnosis and associated disability ${ }^{1}$. Depression may also be secondary to the neuroanatomical and neurochemical changes related to diseaseinduced neurodegeneration. Other factors contributing to the development of depression in MS patients include the loss of leisure opportunities, poor quality of relationships, high stress, and elevated levels of fatigue when compared to healthy individuals ${ }^{3}$.

The pivotal studies of interferon Beta $1 \mathrm{~b}$ and interferon Beta la showed an increase in the risk of suicide and in the prevalence of depression when compared with the placebo group. Patients likely to develop depression are more susceptible ${ }^{5,6}$.

Although depression can exacerbate other MS symptoms, treatments for depression can improve patient adherence rates to other disease-modifying therapies. However, despite the high prevalence of depressive symptoms in patients with MS, limited clinical research using appropriate disease assessment scales exists. Therefore, the objective of the present study was to determine the prevalence and severity of depression, anxiety, and suicidal ideation among patients with MS and their relationship to functional status, disease severity, current treatment and antidepressant use.

\section{METHODS}

This study was approved by the Research and Ethics Committee of the Brasília (Brazil) Health Department (CAAE 22477313.9.0000.5553) and written informed consent was obtained from all patients. For the inclusion of 132 recruited patients, between October 2015 and October 2016, 200 patients diagnosed with the relapsing-remitting clinical form of MS (RRMS) according to the 2010 McDonald's criteria $^{7}$ were evaluated from among a convenience sample of patients attending two specialized MS referral centers located in the Hospital District of Brasília and Hospital Santa Casa in São Paulo, Brazil. All patients were evaluated by two neurologists, one in each department, responsible for the care team of the MS patients.

The inclusion criteria were a confirmed diagnosis of RRMS and an age between 18 and 60 years. The exclusion criteria included patients in the relapse or acute phase of RRMS or the presence of pregnancy and infectious, neoplastic and psychiatric diseases, except for mood disorders, and patients in treatment with other psychiatric medications, such as antipsychotics and anxiolytics.

The attending physicians assessed the patient's level of disability using the Expanded Disability Status Scale (EDSS) ${ }^{8}$, and two neuropsychologists and team of other doctors (trained examiners independent of the patient care team) employed the following three validated scales during their examination: the Beck Depression Inventory-II (BDI-II), Beck Scale for Suicide Ideation (BSI) ${ }^{10}$, and the Hospital Anxiety and Depression Scale (HADS; anxiety subscale: HADS-A; depression subscale: HADS-D $)^{11,12}$.

The disease duration, marital status, and employment status of the patients were also recorded. Patients were classified in accordance with their MS severity, which was determined on the basis of their EDSS score as follows: severe (scores of 6.0-9.5), moderate (3.5-5.5), and mild (0.0-3.0).

The degrees of depression and anxiety were based on the related scales' cutoff points, as follows: no, or minimal, depression BDI-II score of $0-11$, mild depression $=12-19$, moderate $=20-35$ and severe $=36-63$; and this was similar for anxiety. ${ }^{10}$ Absence of, or a depression score of 0 , and a BDI-II indicating depression or anxiety, were scored as yes or no, and the score was used to stratify into two groups and simplify the statistical analysis; that is, patients who scored less than 18.5 points were considered as not being depressed and patients with a score greater than or equal to 18.5 points were considered as depressed ${ }^{13}$. In the HADS score, the abnormal scores range from $11-21^{11,12}$.

The data were analyzed using the PRISM ${ }^{\mathrm{TM}}$ v.6 software (www.graphpad.com/scientific-software/prism). Statistical analyses were performed using Spearman's correlation coefficient test and Fisher's exact test. Differences were considered significant at $\mathrm{p}<0.05$.

Statistical analysis using Spearman's correlation coefficient test identified significant positive correlations between the BDI-II scores and the following parameters: age, EDSS score, and antidepressant use.

A hierarchical regression analysis was performed to evaluate how well the variables of duration of illness, EDSS, HADS-A, BDI and HADS-D scores predicted the suicide ideation as measured by the BSI scale. Age was entered as a statistical control variable. 


\section{RESULTS}

In total, 132 patients with RRMS were analyzed; of these, $22 \%$ (29/132) were men and $78 \%$ (103/132) were women. The mean age of the patients was 35 years (range: 18-65 years). The occupational status among patients was $57.8 \%(48 / 132)$ being active in the workforce, while $42.2 \%$ (35/132) were not [Table 1]. The EDSS mean score for disease-related disability was 2.5 (range: 0.0-7.5). Regarding the duration of the disease, $10.6 \%$ (14/132) of the patients were diagnosed with MS for < 1 year, $41.7 \%$ (55/132) for $1-5$ years, $26.5 \%$ (35/132) for 5 -10 years and $21.3 \%$ (28/132) were diagnosed for $>10$ years. (Table 1)

The current treatment of each patient at the time of the research was interferon (24.2\% [32/132 patients]), glatiramer acetate (8.3\% [11/132]), fingolimod (32.6\% [43 / 132]), dimethyl fumarate $(8.3 \%$ [11/132]), natalizumab $(15.2 \%$ [20/132]), teriflunomide (4.5\% [6/132]), alemtuzumab $0.8 \%$ [1/132]) and vitamin D (1.5\% [2/132]). Overall, 4.5\% (6/132) of the patients were not taking any medication for MS. Regarding the use of antidepressants, $34.8 \%$ (47/132) of the patients were taking antidepressants, while $65.1 \%(85 / 132)$ were not.

According to the HADS scores, a mean of $7.6 \%$ of patients experienced anxiety, and $5.9 \%$, depression. According to the BDI-II, $34 \%$ of the patients presented with depression The BSI scores of the patients revealed that $2.1 \%$ had suicidal ideation. Among the patients in our sample, four patients had attempted suicide, and of these, two were taking interferon while the other were taking fingolimod (Tables 2 and 3).

Table 1. Demographic characteristics of the sample of the 132 Brazilian multiple sclerosis patients.

\begin{tabular}{|c|c|c|}
\hline Variable & Frequency & $\%$ \\
\hline \multicolumn{3}{|l|}{ Gender } \\
\hline Male & 29 & 22 \\
\hline Female & 103 & 78 \\
\hline \multicolumn{3}{|l|}{ Education } \\
\hline Fundamental & 9 & 6.8 \\
\hline Undergraduate & 55 & 41.7 \\
\hline Graduate & 55 & 41.7 \\
\hline Postgraduate & 13 & 9.8 \\
\hline \multicolumn{3}{|c|}{ Occupational status } \\
\hline Active & 48 & 57.8 \\
\hline Inactive & 35 & 42.2 \\
\hline \multicolumn{3}{|l|}{ Marital status } \\
\hline Married & 45 & 54.2 \\
\hline Single & 38 & 45.8 \\
\hline \multicolumn{3}{|l|}{ Antidepressants } \\
\hline No & 85 & 64.4 \\
\hline Yes & 47 & 35.6 \\
\hline
\end{tabular}

The correlations were significant and positive, and ranged from low to moderate, associations among the variables. The BDI-II scores were correlated with age $(r=0.30, p=0.008)$, EDSS score $(r=0.40, P=0.0006)$, and antidepressant use $(\mathrm{r}=0.27, \mathrm{p}=0.01)$ [Tables 1 and 2]. The HADS-A scores correlated with the EDSS score $(r=0.26, p=0.02)$ and age $(r=0.35$, $\mathrm{p}=0.02)$. The HADS-D scores correlated with antidepressant use $(r=0.33, P=0.003)$. The BSI scores correlated with antidepressant use $(r=0.22, p=0.05)$ and the EDSS scores $(r=0.27$, $p=0.02)$. Lastly, the EDSS score correlated with the antidepressant use $(r=0.30, p=0.01)$ (Table 4).

Table 2. Subgroups of RRMS patients by use of two different DMTs (interferon and fingolimod): BDI-II, HADS, BSI and suicide attempt.

\begin{tabular}{ccccc}
\hline \multirow{2}{*}{ Variable } & \multicolumn{2}{c}{ BDI-II } & & $95 \% \mathrm{Cl}$ \\
\cline { 2 - 2 } & Depression Nopression & p-value OR Lower Upper
\end{tabular}

Interferon use

$\begin{array}{lcccccc}\text { Yes } & 6 & 26 & 0.03 & 0.361 & 0.136 & 0.956 \\ \text { No } & 39 & 61 & & & & \end{array}$

\begin{tabular}{ccccccc}
\multicolumn{3}{l}{ HADS-A classification } \\
Yes & 8 & 24 & 0.06 & 0.442 & 0.181 & 1.079 \\
No & 43 & 57 & & & &
\end{tabular}

HADS-D classification

$\begin{array}{lcccccc}\text { Yes } & 5 & 27 & 0.37 & 0.62 & 0.214 & 1.793 \\ \text { No } & 23 & 77 & & & & \end{array}$

\begin{tabular}{ccccccc}
\multicolumn{3}{l}{ BSI classification } \\
Yes & 5 & 28 & 0.15 & 0.476 & 0.167 & 1.360 \\
No & 28 & 72 & & & & \\
\end{tabular}

Suicide attempt

$\begin{array}{lllllll}\text { Yes } & 2 & 30 & 1.00 & 0.767 & 0.154 & 3.810 \\ \text { No } & 8 & 92 & & & & \end{array}$

Fingolimod use

$\begin{array}{lllllll}\text { Yes } & 16 & 27 & 0.59 & 1.226 & 0.573 & 2.624 \\ \text { No } & 29 & 60 & & & & \end{array}$

HADS-A classification

$\begin{array}{lllllll}\text { Yes } & 19 & 24 & 0.36 & 1.410 & 0.672 & 2.960 \\ \text { No } & 32 & 57 & & & & \end{array}$

\begin{tabular}{ccccccc}
\multicolumn{4}{l}{ HADS-D classification } \\
Yes & 13 & 30 & 0.07 & 2.138 & 0.909 & 5.028 \\
No & 15 & 74 & & & &
\end{tabular}

BSI classification

$\begin{array}{lllllll}\text { Yes } & 12 & 31 & 0.59 & 1.253 & 0.548 & 2.865 \\ \text { No } & 21 & 68 & & & & \end{array}$

Suicide attempt

$\begin{array}{lllllll}\text { Yes } & 4 & 39 & 0.72 & 1.419 & 0.379 & 5.317 \\ \text { No } & 6 & 83 & & & & \end{array}$

RRMS: relapsing remitting multiple sclerosis; DMTs: disease modifying therapies; BDI-II: Beck Depression Inventory-II; OR: odds ratio; $\mathrm{Cl}$ : confidence interval; HADS-A: Hospital Anxiety and Depression Scale anxiety subscale; HADS-D: Hospital Anxiety and Depression Scale depression subscale; BSI: Beck Scale for Suicide Ideation. 
Table 3. Results of categorical associations: antidepressant, DMTs (interferon and fingolimod), BDI-II, HADS, BSI and suicide attempt.

\begin{tabular}{|c|c|c|c|c|c|c|c|}
\hline \multirow{2}{*}{ Variable } & \multirow{2}{*}{$\begin{array}{l}\text { Categorical } \\
\text { associations }\end{array}$} & \multicolumn{2}{|c|}{ Suicide Attempt } & \multirow{2}{*}{$p$-value } & \multirow{2}{*}{ OR } & \multicolumn{2}{|c|}{$95 \% \mathrm{Cl}$} \\
\hline & & Yes & No & & & Lower & Upper \\
\hline \multirow{2}{*}{ BSI classification } & Yes & 5 & 28 & 0.058 & 3.357 & 0.906 & 12.435 \\
\hline & No & 5 & 94 & & & & \\
\hline \multirow{2}{*}{ BDI-II } & Yes & 6 & 39 & 0.089 & 3.192 & 0.852 & 11.964 \\
\hline & No & 4 & 83 & & & & \\
\hline \multirow{2}{*}{ HADS-A classification } & Yes & 6 & 45 & 0.184 & 2.567 & 0.687 & 9.584 \\
\hline & No & 4 & 77 & & & & \\
\hline \multirow{2}{*}{ HADS-D classification } & Yes & 5 & 23 & 0.035 & 4.304 & 1.150 & 16.113 \\
\hline & No & 5 & 99 & & & & \\
\hline \multirow{2}{*}{ Antidepressant } & Yes & 4 & 43 & 0.744 & 1.225 & 0.328 & 4.578 \\
\hline & No & 6 & 79 & & & & \\
\hline \multirow{2}{*}{ Interferon } & Yes & 2 & 30 & 1.00 & 0.767 & 0.154 & 3.810 \\
\hline & No & 8 & 92 & & & & \\
\hline \multirow{2}{*}{ Fingolimod } & Yes & 4 & 39 & 0.728 & 1.419 & 0.379 & 5.317 \\
\hline & No & 6 & 83 & & & & \\
\hline \multirow{4}{*}{ Disease duration (years) } & $<1$ & 0 & 14 & 0.724 & & & \\
\hline & $1-5$ & 5 & 50 & & & & \\
\hline & $5-10$ & 2 & 33 & & & & \\
\hline & $>10$ & 24 & 7 & & & & \\
\hline
\end{tabular}

DMTs: disease modifying therapies; BDI-II: Beck Depression Inventory-II; OR: odds ratio; Cl: confidence interval; HADS-A: Hospital Anxiety and Depression Scale anxiety subscale; HADS-D: Hospital Anxiety and Depression Scale depression subscale; BSI: Beck Scale for Suicide Ideation.

Table 4. Multiple hierarchical regression - Age, MS duration, EDSS, and Anxiety and Depression Scales r2 of model: 0.273; p-value of model $<0.0005$.

\begin{tabular}{lcc}
\hline Variable & Beta coefficient & $p$-value \\
\hline Age & -0.046 & 0.185 \\
Duration (months) & 0.001 & 0.878 \\
EDSS & -0.017 & 0.928 \\
HADS-A & -0.183 & 0.057 \\
BDI-II & 0.219 & $<0.0005$ \\
HADS-D & 0.182 & 0.195
\end{tabular}

EDSS: Expanded Disability Status Scale; HADS-A: Hospital Anxiety and Depression Scale anxiety subscale;HADS-D: Hospital Anxiety and Depression Scale depression subscale; BDI-II: Beck Depression Inventory-II.

No significant association was found between the subgroups of patients treated with different disease modifying therapies and the presence of anxiety, depression and suicidal ideation (Fisher's exact test; Tables 2 and 3).

\section{DISCUSSION}

The aim of the present study was to investigate the relationships among MS, anxiety, depression, and suicidal ideation. Here, the patients' mean age (35 years) and ratio of women to men were comparable to those reported previously, supporting that MS predominately affects women and young adults ${ }^{13,14}$. Interestingly, we found higher proportions of depression and anxiety symptoms and a higher rate of suicidal ideation in patients with MS when compared to the general population. In our sample, the presence of depressive symptoms, measured by the EDSS score, was found in $34 \%$ of the patients $(n=45)$, who had a higher median age (38 years), EDSS score (3.1) and disease duration (2.6 years) when compared with the patients without depressive symptoms. As well, higher scores on this scale appeared to have a direct correlation with the risk of suicide in patients with MS, as shown by the correlation score $(\mathrm{r}=0.27)$ and confirmed by the regression model designed.

Similar to previous literature, our data showed a high prevalence of depressive symptoms in patients with $\mathrm{MS}^{14,15,16}$. Additionally, we identified a higher prevalence of depression in our patients with MS than that reported for the general population $^{16}$, with $30.6 \%, 29.3 \%$, and $5.3 \%$ of our patients exhibiting mild, moderate, and severe depressive symptoms, respectively. Although $34 \%$ of our patients with MS had depression according to the BDI-II scale, only $33.3 \%$ were on antidepressants, indicating that this comorbidity is often not suspected or identified during the clinical assessments of these patients and that few effective therapeutic measures against depression, including both pharmacological and non-pharmacological strategies, are employed in patients with MS. Consistent with the findings of other studies ${ }^{1,15,17,18}$, we found that age, EDSS score, disease duration, and occupational status were important factors associated with depression in patients with MS, based on the correlation of these parameters and the higher scores in the HADS and BDI-II scales. 
The present study identified positive correlations, moderately between the EDSS score and presence of depression, as measured with the BDI-II, and lower between the EDSS score and presence of suicidal ideation, as measured with the BSI. This relationship suggests simultaneity between disease progression and psychiatric disorders. Additionally, as reported previously, the relationship between the high rate of depression and suicidal ideation, through disease evolution, side effects from MS, or the associated symptoms, is complex ${ }^{7}$. However, our study confirms the importance of these comorbidities in patients with MS and emphasizes the need for early diagnosis and treatment. The high level of suicidal ideation we identified in our patients with MS is noteworthy. Moreover, there was a lower significant correlation between depression, as measured with the EDSS, and suicidal ideation, as measured with the BSI, in patients with MS. A study by de Cerqueira et al. ${ }^{1}$, involving 60 patients with MS, demonstrated that $16.6 \%$ of the participants had a past history of suicide attempt or current suicide risk and noted that comorbidity with depression was significantly higher in patients with a risk of suicide than it was in a control group. Therefore, despite the intensity of the correlation, it is clear that depression can affect the quality of life, and the relationship of these parameters with the increased risk of death via suicide in individuals with MS, should alert clinicians to the issue. Hence, it is essential that researchers and clinicians effectively address this issue in both the laboratory and clinical practice.

When examining the link between MS medications and the presence of psychiatric disorders, we were unable to identify a relationship between patients who used immunomodulatory or immunosuppressive treatments and the presence of depression, anxiety, and suicidal ideation. However, this conclusion is limited because over a third of the patients in our sample were taking antidepressants. On the other hand, studies such as the REGAIN study ${ }^{20}$ and EPOC study ${ }^{21}$ presented divergent conclusions regarding whether treatment with fingolimod, with or without antidepressants, causes or reduces depression in patients with MS. Other recent studies, such as the Consortium of MS Centers by Mirsky et al. ${ }^{22}$ in which they used a large database, affirm that there was no influence of interferon beta and use of antidepressants compared with other disease-modifying therapies, as in the present study.

This study has one major limitation. After being stratified for analysis, the present study was limited in terms of the size of the analytical sample. Since this was a cross-sectional study with a convenience sample, the sample size was small and unidentified confounding factors may have affected the results. Studies with larger sample sizes and different designs need to be conducted to confirm our findings.

Our findings support the use of systematic evaluations for psychiatric disorders in patients with MS, as the incidences of depressive symptoms, anxiety symptoms, and suicidal ideation are higher in these patients than they are in the general population. The presence of depressive symptoms in our sample suggests that depression has a direct influence on the risk of suicide in patients with MS, indicating that such comorbidities need to be treated appropriately to avoid negative outcomes.

\section{Acknowledgments}

We thank Prof. Dr. Cesar Augusto Silva for providing statistical study and analysis of data. We thank Mrs. Ligia Machado for organizing the schedule of patient visits.

\section{References}

1. Cerqueira AC, Andrade PS, Godoy-Barreiros JM, Silva ACO, Nardi AE. Risk factors for suicide in multiple sclerosis: a case-control study. J Bras Psiquiatr. 2015;64(4):303-6. https://doi.org/10.1590/0047-2085000000093

2. Capkun G, Dahlke F, Lahoz R, Nordstrom B, Tilson HH, Cutter $\mathrm{G}$ et al. Mortality and comorbidities in patients with multiple sclerosis compared with a population without multiple sclerosis: an observational study using the US Department of Defense administrative claims database. Mult Scler Relat Disord. 2015 Nov;4(6):546-54. https://doi.org/10.1016/j.msard.2015.08.005

3. Coughlin SS, Sher L. Suicidal behavior and neurological illnesses. J Depress Anxiety. 2013 Apr;Suppl 9(1):12443. https://doi.org/10.4172/2167-1044.S9-001

4. Gramaglia C, Feggi A, Bergamasco P, Bert F, Gattoni E, Marangon $D$ et al. Clinical characteristics associated with suicide attempts in clinical settings: a comparison of suicidal and non-suicidal depressed inpatients. Front Psychiatry. 2016 Jun;7:109. https://doi.org/10.3389/fpsyt.2016.00109

5. Machado S. Recomendações esclerose múltipla. São Paulo: Omnifarma; 2012.
6. Patten SB, Metz LM. Interferon beta-1 a and depression in relapsing-remitting multiple sclerosis: an analysis of depression data from the PRISMS clinical trial. Mult Scler. 2001 Aug;7(4):243-8. https://doi.org/10.1177/135245850100700406

7. McDonald WI, Compston A, Edan G, Goodkin D, Hartung HP, Lublin FD et al. Recommended diagnostic criteria for multiple sclerosis: guidelines from the International Panel on the diagnosis of multiple sclerosis. Ann Neurol. $2001 \mathrm{Jul} ; 50(1): 121-7$. https://doi.org/10.1002/ana.1032

8. Kurtzke JF. Rating neurologic impairment in multiple sclerosis: an expanded disability status scale (EDSS). Neurology. 1983 Nov;33(11):1444-52. https://doi.org/10.1212/WNL.33.11.1444

9. Beck AT, Ward CH, Mendelson M, Mock J, Erbaugh J. An inventory for measuring depression. Arch Gen Psychiatry. 1961 Jun;4(6):561-71. https://doi.org/10.1001/archpsyc.1961.01710120031004

10. Cunha JA. Manual da versão em português das escalas Beck. São Paulo: Casa do Psicólogo; 2001.

11. Botega NJ, Ponde MP, Medeiros P, Lima MG, Guerreiro CAM. [Validation of the Hospital Anxiety and Depression Scale (HAD) in ambulatory epileptic patients]. J Bras Psiquiatr. 1998;47(6):285-9. 
12. Zigmond AS, Snaith RP. The hospital anxiety and depression scale. Acta Psychiatr Scand. 1983 Jun;67(6):361-70. https://doi.org/10.1111/j.1600-0447.1983.tb09716.x

13. Sacco R, Santangelo G, Stamenova S, Bisecco A, Bonavita S, Lavorgna L et al. Psychometric properties and validity of Beck Depression Inventory II in multiple sclerosis. Eur J Neurol. 2016 Apr;23(4):744-50. https://doi.org/10.1111/ene.12932

14. Grytten N, Aarseth JH, Lunde HM, Myhr KM. A 60-year followup of the incidence and prevalence of multiple sclerosis in Hordaland County, Western Norway. J Neurol Neurosurg Psychiatry. 2016 Jan;87(1):100-5. https://doi.org/ 10.1136/jnnp-2014-309906

15. Mendes MF, Tilbery CP, Balsimelli S, Moreira MA, Barão-Cruz AM. [Depression in relapsing-remitting multiple sclerosis]. Arq Neuropsiquiatr. 2003 Sep;61(3A):591-5. Portuguese. https://doi.org/10.1590/S0004-282X2003000400012

16. Seyed Saadat SM, Hosseininezhad M, Bakhshayesh B, Seyed Saadat SN, Nabizadeh SP. Prevalence and predictors of depression in Iranian patients with multiple sclerosis: a population-based study. Neurol Sci. 2014 May;35(5):735-40. https://doi.org/10.1007/s10072-013-1593-4

17. Johansson S, Gottberg K, Kierkegaard M, Ytterberg C. Variations in and predictors of the occurrence of depressive symptoms and mood symptoms in multiple sclerosis: a longitudinal two-year study. BMC Neurol. 2016 Mar;16(1):32. https://doi.org/10.1186/s12883-016-0551-1
18. Silva MT, Galvao TF, Martins SS, Pereira MG. Prevalence of depression morbidity among Brazilian adults: a systematic review and meta-analysis. Rev Bras Psiquiatr. 2014 Sep;36(3):262-70. https://doi.org/10.1590/1516-4446-2013-1294

19. Bamer AM, Cetin K, Johnson KL, Gibbons LE, Ehde DM. Validation study of prevalence and correlates of depressive symptomatology in multiple sclerosis. Gen Hosp Psychiatry. 2008 Jul-Aug;30(4):311-7. https://doi.org/10.1016/j.genhosppsych.2008.04.006

20. Bayas A, Schuh K, Baier M, Vormfelde SV, Koppai-Reiner J, Strauss E et al.; REGAIN Study Group. Combination treatment of fingolimod with antidepressants in relapsing-remitting multiple sclerosis patients with depression: a multicentre, open-label study - REGAIN. Ther Adv Neurol Disorder. 2016 Sep;9(5):378-88. https://doi.org/10.1177/1756285616651197

21. Fox E, Edwards K, Burch G, Wynn DR, LaGanke C, Crayton $\mathrm{H}$ et al. Outcomes of switching directly to oral fingolimod from injectable therapies: results of the randomized, open-label, multicenter, Evaluate Patient OutComes (EPOC) study in relapsing multiple sclerosis. Mult Scler Relat Disord. 2014 Sep;3(5):607-19. https://doi.org/10.1016/j.msard.2014.06.005

22. Mirsky MM, Marrie RA, Rae-Grant A. Antidepressant drug treatment in association with multiple sclerosis disease-modifying therapy: using Explorys in the MS population. Int J MS Care. 2016 NovDec;18(6):305-10. https://doi.org/10.7224/1537-2073.2016-056 